\title{
Forecasting Tourism Demand Using Time Series, Artificial Neural Networks and Multivariate Adaptive Regression Splines: Evidence from Taiwan
}

\author{
Chang-Jui Lin (Corresponding author) \\ Graduate School of Business Administration, Fu Jen Catholic University \\ No. 499, Sec., 4, TamKing Rd., Tamsui Dist., New Taipei City 25135, Taiwan \\ Tel: +886-02-28013131-6582 E-mail: rayraylin@seed.net.tw
}

Hsueh-Fang Chen

Yu Da University and Graduate School of Business Administration, Fu Jen Catholic University No. 168, Hsueh-fu Rd., Tanwen Village, Chaochiao Township, Miaoli County, 36143 Taiwan

E-mail: hfang@webmail.ydu.edu.tw

Tian-Shyug Lee

College of Management, Fu Jen Catholic University

No.510, Zhongzheng Rd., Xinzhuang Dist., New Taipei City 24205, Taiwan

E-mail: badm1004@mail.fju.edu.tw

Received: January 13, $2011 \quad$ Accepted: February 23, 2010 doi:10.5430/ijba.v2n2p14

\begin{abstract}
In the past few decades, international tourism has grown rapidly and has become a very interesting topic in tourism research. Taiwan, acting as a citizen in the global community, improved traveling facilities, and governments' strong promotion has drawn more and more visitors to visit Taiwan. This study tries to build the forecasting model of visitors to Taiwan using three commonly adopted ARIMA, artificial neural networks (ANNs), and multivariate adaptive regression splines (MARS). In order to evaluate the appropriateness of the proposed modeling approaches, the dataset of monthly visitors to Taiwan was used as the illustrative example. Analytic results demonstrated that ARIMA outperformed ANNs and MARS approaches in terms of RMSE, MAD, and MAPE and provided effective alternatives for forecasting tourism demand.
\end{abstract}

Keywords: Tourism demand forecasting, ARIMA, Artificial neural networks, Multivariate adaptive regression splines

\section{Introduction}

The rapid global development of tourism industry in the recent 20 years has contributed relatively highly to the economy in every country. According to the research data from the World Travel \& Tourism Council (WTTC), the output value of the global tourism (including tourism-related industries, investments and taxations, etc.) was 5.474 trillion U.S. dollars, generating $9.4 \%$ of global GDP in 2009 . The output value of the global tourism industry is expected to reach 10.478 trillion U.S. dollars and generate $9.5 \%$ of global GDP by 2019. The information from WTTC showed that the global tourism industry employers constituted 2.1981 hundred million people, generating $7.6 \%$ of the world's workforce. It is expected that by 2019 , the global tourism industry will employ about 275.688 million people and generate about $8.4 \%$ of the world's workforce. From this, the contribution of worldwide tourism industry to the global economic development is significantly important. It shows a tendency of growth in the future. In the next ten years, it might create employment opportunities for 55.878 millions people.

In such cases, the governments of each nation should pay much attention to the growth of the number of tourists in their countries. Thus, forecasting the tourism demand becomes very important. With a correct tourism demand forecasting model that could validly predict the tourism demand, the government would be able to invest properly and effectively to 
build tourist infrastructures. After investing in the airlines, buses, tourist hotels, restaurants, amusement parks, souvenir shops, shopping malls, among others, the private sectors will not experience operating loss from small number of tourists. A comfortable and enjoyable travel itinerary can provide tourists with a great travel experience and increase their likelihood of returning. Therefore, a highly valid forecast of the tourism demand would have a positive influence on the government, the private sectors, and the tourists.

In order to develop tourism industry in Taiwan, Tourism Bureau proposed Project Vanguard for Excellence in Tourism in 2009. Within the 4 years, from 2009 to 2012, the government is expected to invest 9.1 hundred million USD while the private enterprises are expected to invest 60.6 hundred million USD. Hopefully, it will increase the number of tourists from 3.84 million people in 2008 to 5.5 million people in 2012 and increase the foreign exchange earnings from 5.1 billion USD, generating 1.34\% of Taiwan's GDP in 2007, to 90 billions USD, exceeding 2\% of Taiwan's GDP in 2012. The growth in the number of sightseeing tourists in Taiwan will affect the return on investments of the Taiwan's government and the private sectors. Therefore, the accuracy of forecasting the number of tourists who will come to Taiwan for sightseeing will significantly determine the success of the entire project. A model for forecasting tourism demand in Taiwan is essential for the tourist industry in Taiwan.

Song and $\mathrm{Li} \mathrm{(2008)} \mathrm{have} \mathrm{conducted} \mathrm{a} \mathrm{meta-analysis} \mathrm{of} \mathrm{studies} \mathrm{on} \mathrm{tourism} \mathrm{demand} \mathrm{and} \mathrm{forecasting} \mathrm{from} 2000$ to 2007. They have reviewed 121 articles from which 72 articles utilized time-series method to evaluate the tourism demand and forecasting, 71 articles used the econometric method to establish the tourism demand and forecasting, and more than 30 articles used both the time-series method and the econometric method to evaluate the tourism demand and forecasting. In addition, other methods, such as the artificial neural network (ANN), the rough set method, the fuzzy time series (Fuzzy), and genetic algorithms (GAs), among others, were also used. Hence, it has been shown that the most utilized methods include the time-series method and the econometric method in addition to other less frequently used methods, such as ANN, Fuzzy and GAs, among others.

In Taiwan, few studies investigated tourism demand modeling and forecasting. Huang and Min (2002) conducted the research on the effect of the earthquake of a 7.3 magnitude on Richter scale that hit Taiwan on September 21, 1999 on tourism demand and the recovery of tourism. Min (2005) has researched the effect of SARS, which took place on March 15, 2003 in Taiwan, on the demand for tourists in Taiwan. The above studies aimed to investigate the demand for tourists in Taiwan during the major disasters. Huarng, Moutinho, Luiz and Yu (2006) have used the model for neural-based fuzzy time-series and time-series (ARIMA) for forecasting the demand for tourists. In this study, the three methods of time-series analysis (ARIMA), neural (ANN), and cloud-shaped regression (MARS) were used to investigate the forecasts for the demand for tourists to establish the tourism demand model and forecast as well as to compare the forecasting effects established by different methods.

Time series is a common used forecasting model with significant accuracy. ANN and MARS have significant forecasting ability in classification, while MARS has never been used in tourism demand forecasting. However, in this study, three methods - ARIMA, ANN and MARS are used to forecast tourism demand in Taiwan, trying to understand the applicability of using Time series, ANN and MARS in tourism demand forecasting and which model is the most correct one.

\section{Literature Review}

The time-series method, the econometric method, ARIMA, ANN, and GAs are the most commonly used methods to model tourism demand and forecasting (Song \& Li 2008). However, many scholars use a single type of method, either the time-series method, the econometric method, or the ANN to model tourism demand and forecasting. Kulendran and Shan (2002) have analyzed the demand for tourists in Mainland China using ARIMA model and Huang and Min (2002) have analyzed the demand for tourists in Taiwan also using ARIMA model. Lim and McAleer (2002) as well as Kim and Moosa (2005) have analyzed the demand for tourists in Australia using ARIMA model. Coshall (2005) has modeled the British sightseeing tourists in Europe using ARIMA model. From above, it can be summarized that many researchers have already analyzed the demand for tourists using ARIMA model.

Law (2000) has used the Back-propagation model of ANN analysis to investigate the demand for Taiwan tourists in Hong Kong. Palmer, Jose Montano and Sese (2006) used the ANN time-series model to predict the consumption of tourists in the Balearic Islands (Spain). ANN model is able to analyze the tourism demand; however, the model that gives a more valid prediction, whether it is ARIMA or ANN model, should be considered in the analysis.

Some scholars have simultaneously analyzed tourists demand by different types of methods in order to understand which method models tourism demand and forecasting the best. Burger, Dohnal, Kathrada and Law (2001) have used the monthly data and ARIMA, genetic regression (GMDH) group method of data handling, and the ANN method to model 
tourism demand and forecasting in South African. It was found that the error rate established by ANN model is the lowest. Cho (2003) used the monthly data and the three methods of Exponential smoothing, ARIMA, and ANN to predict the number of tourists from the United States, Japan, Taiwan, South Korea, the United Kingdom, Singapore, and other regions to Hong Kong. The ANN model performed the best.

De Gooijer, Ray and Krager (1998) used the Time-series Multivariate adaptive regression splines (TSMARS-time series MARS) for conducting the exchange rate prediction. The MARS model is seldom used to model tourism demand and forecasting. However, as seen from De Gooijer et al.'s (1998) study, the MARS can be used to model tourism demand and forecasting in order to understand whether it performs better compared to other forecasting methods.

\section{Research Methods}

\subsection{Time-series analysis (ARIMA)}

Box and Jenkins (1976) developed time-series analysis ARIMA (autoregressive integrated moving average) model. It consists of three parts, auto regression $\operatorname{AR}(p)$, moving averages MA(q) and differencing in order to strip off the integration (I) of the series) (d) and forms ARIMA (p,d,q).

This linear model is as follows (Pankratz, 1983, p.281)

$$
\phi_{p}(B) \Phi_{s p}\left(B^{L}\right) \nabla^{\mathrm{d}} \nabla_{L}^{s d} Z_{t}=\Theta_{s q}\left(B^{L}\right) \theta_{q}(B) \varepsilon_{t}
$$

B refers to the backshift operator; $Z_{t}$ refers to the information for the time $\mathrm{t} ; \varepsilon_{t}$ refers to the distribution of time $\mathrm{t}$. non-seasonal operator, $\phi_{P}(B)=\left(1-\phi_{1} B-\phi_{2} B-\cdots-\phi_{P} B\right)$. Season computing factor $\Phi_{s p}\left(B^{L}\right)=$ $\left(1-\Phi_{1 L} B^{L}-\Phi_{2 L} B^{L}-\cdots-\Phi_{s p} B^{L}\right)$, Non-seasonal operator $\theta_{q}(B)=\left(1-\theta_{1} B-\theta_{2} B-\cdots-\theta_{q} B\right)$, Season computing factor $\Theta_{s q}\left(B^{L}\right)=\left(1-\Theta_{1} B^{L}-\Theta_{2 L} B^{L}-\cdots-\Theta_{s q L} B^{L}\right)$, Non-seasonal differencing operator $\nabla^{d}$ is $(1-B)^{d}$, Season differential operator factor $\nabla_{L}^{s d}$ is $\left(1-B^{L}\right)^{s d}$.

\subsection{Artificial Neural Network (ANN)}

Artificial Neural Network (ANN) is a science of simulating human brain cells using a computational model. Freeman and Skapura (1992) believed that a neural network was an information processing system that uses a large number of artificial nerve cells to imitate a biological neural network. Thus, the computer can also simulate a human neural structural system for data processing. Its conceptual approach is shown in Figure 1.

\section{$<$ Figure 1 about here $>$}

As the neural network possesses segmentation and identification ability (Zhang, Patuwo \& $\mathrm{Hu}, 1998$ ), it is widely used in various commercial and financial aspects, e.g., credit card fraud judgment, stock prices, exchange rates, interest rates and bankruptcy prediction. Financial analysis, among others, as well as in various scientific applications, e.g., weather forecasting, for medical images judgment, and fingerprint recognition system, among others (Berry \& Linoff, 1997; Fish, Barnes, \& Aiken, 1995; Lee \& Chiu, 2002; Lee, Chiu, Lu \& Chen, 2002; Vellido, Lisboa \& Vaughan, 1999; Leung, Chen \& Daouk, 2000; Chiu, Shao \& Lee, 2003).

\section{$<$ Figure 2 about here $>$}

Many sophisticated models have been proposed during the development of neural network. They can be divided into 3 structural networks of learning strategies: supervised learning, non-supervised learning, and associative learning. Among all the network models, the back-propagation network (BPN) of supervised learning is the most representative and the most widely used. According to the research of Vellido et al. (1999), 78\%of the researchers used the BPN type of artificial neutral network in the commercial aspects between 1992 and 1998. This is quite a high proportion. They chose BPN because it has the advantages of a high learning accuracy and quick retrospect speeds; hence, BPN is also used as an analytical tool in this study.

The structure of Back-propagation neural network (BPN) is divided into three layers: input layer, hidden layer, and output layer. Neurons in the input layer predict output values. Hidden layer is the conversion layer in the neural network representing the interaction of the neurons. The neurons in the output layer represent the final output value. This study uses BPN model as shown in Figure 2.

\subsection{Multivariate Adaptive Regression Splines (MARS)}

Multivariate Adaptive Regression Splines (MARS) is a form of multi-variable non-parametric regression analysis introduced by the statistician and physicist Friedman (1991). It is a new way of dealing with diverse information and issues. The basic idea is to add up sections of spline's basis function (BF) to form a flexible MARS prediction model, to determine the value of the function of the basic equations by referring to the cross-validation among the parameters, and to assess its loss of fit (LOS) by the judging criteria in order to get the best and the most suitable variables set, knots, and 
the interaction to solve various high-dimensional data problems. It is a flexible regression analysis and can automatically create an accurate model for speculating the continuous and discrete response variables (Friedman, 1991).

$\hat{f}(x)=a_{0}+\sum_{p=1}^{M} a_{m} \prod_{k=1}^{K_{m}}\left[s_{k m} \cdot\left(x_{v(k, m)}-t_{k m}\right)\right]_{+}$

The above formula is a common MARS model, in which BF is the multiple regressed section (see below), which changes mainly based on demand.

$B_{m}(x)=\prod_{k=1}^{K_{m}} H\left[s_{k m} \cdot\left(x_{v(k, m)}-t_{k m}\right)\right]_{+}$

$\mathrm{a}_{0}$ and $\mathrm{a}_{\mathrm{m}}{ }_{\mathrm{m}}$ are the parameter values and their functions are similar to the regression coefficient of the linear regression model. M is BF's quantity determined by the judgment criteria; Km is the knot quantity; the value of Skm is +1 or- 1 and its function is to show the direction; $\mathrm{v}(\mathrm{k}, \mathrm{m})$ is the variable label; tkm is the cut-off point (value). In a given target variable and an optional set of forecasting variables, MARS establishes and adjusts all the models automatically. It includes separating the significant variables from the more inappropriate variables, determining the interaction among the variables, adopting a new variable clustering technique to deal with the problem of the missing value, and using a large number of self-tests to avoid over-fitting (Steinberg, Bernard, Phillip \& Kerry, 1999).

We can see BF as the explanatory formula for each of the sections respectively. Each BF is the value of significant variables determined by judging criteria and LOF as well as by finding out the appropriate knot and its interaction using forward and backward algorithm simultaneously to solve the high-dimensional data problem. It is a very flexible regression analysis. It can establish an accurate model rapidly and automatically in order to speculate its continuous or binary variables (Friedman, 1991). To determinate the value of BF in accordance with LOF, it is important to determine whether BF significantly contributes to the outcome after each of its entry and to remove the non-contributed BF and retain the contributed $\mathrm{BF}$ in the main model.

\section{Empirical results and analysis}

\subsection{Research data}

In this study, the sample comprises the aggregate number of tourists who arrive in Taiwan every month. Occurrence of SARS in Taiwan in March 15, 2003, immediately affected the number of tourists in Taiwan but this number returned to normal in 2004. Therefore, the data were obtained between January 2004 and June 2010, covering a total of 78 months. The data from the preceding 62 months were used as training samples for modeling and forecasting tourism demand in Taiwan. The data between March 2009 and June 2010 covering 16 months was used to establish the forecasting model predicting the number of tourists coming to Taiwan for sightseeing. We compared the models established by three different methods to determine the one that performs the best. Tourists come to Taiwan for different reasons, for instance, business, sightseeing, visiting relatives and friends, participating in conferences, studying, and other reasons. The data for this study were obtained from the Monthly Tourism Statistics issued by Tourism Bureau Ministry of Transportation and Communication (ROC).

\subsection{Time-series Analysis (ARIMA)}

The previous data covering 62 months from January 2004 to February 2009 was used to establish the tourism demand forecasting model. Consequently, we compared the predicted number and the actual number of tourists who visited Taiwan during the following 16 months from March 2009 to June 2010 in order to understand the accuracy of the model.

A single root test was used to test the data from the initial 62 months. The results revealed no single root for the intercept items and tendency. Thus, these data reflect a stationary time series, which was then tested using ARIMA analysis. First, we conducted ARIMA $(1,0,0)$ analysis and found a seasonal ARIMA. In the next step, we analyzed the 17 models using the seasonal ARIMA, as shown in Table 1. They are from $\operatorname{ARIMA}(1,0,2) \times(1,0,0)_{12}$ to $\operatorname{ARIMA}(2,0,1) \times(2,0,2)_{12}$. These 17 models' autocorrelation function (ACF) indicated $\mathrm{p}$ values greater than $5 \%$, the residuals of the Jarque-Bera normality test $\mathrm{p}$ values greater than $5 \%$, and residuals that meet the normal distribution assumptions. Further, we compared the adjusted $\mathrm{R}^{2}$, AIC, and SBC and found that in $\operatorname{ARIMA}(1,0,1) \times(1,0,2)_{12}$, ARIMA $(1,0,0) \times(2,0,1)_{12}, \operatorname{ARIMA}(2,0,0) \times(2,0,1)_{12}$, $\operatorname{ARIMA}(1,0,0) \times(2,0,2)_{12}$ and $\operatorname{ARIMA}(2,0,0) \times(2,0,2)_{12}$, the value of adjusted $\mathrm{R}^{2}$ of was greater than $0.79 \%$, the value of AIC was below 21.57, and the value SBC was below 21.8. Above five models fit the data best.

$<$ Table 1 about here $>$

Table 2 compares the results of the predicted number and the actual number of tourists who visited Taiwan between March 2009 and June 2010 using the 17 models. It was found that the values of RMSE, MAD, and MAPE of $\operatorname{ARIMA}(2,0,0) \times(2,0,2)_{12}$ are the smallest among the 17 seasonal ARIMA models, thus, $\operatorname{ARIMA}(2,0,0) \times(2,0,2)_{12}$ is the best ARIMA model.

$<$ Table 2 about here $>$ 


\subsection{Artificial Neural Network (ANN)}

To establish the BPN model for tourism demand forecasting in Taiwan, we used the data for previous 62 months as training samples and the data for the following 16 months as test samples. In the training samples, the number of tourists provided the data for the output layer while the number of tourists in Taiwan during the previous 12 months provided the data for the input layer. The hidden layer was set as 22 to 26 neurons and the output layer as 1 neuron. The learning rate was set between 0.0002 and 0.0006 with iterations between 50000 and 150000 for the best prediction model analysis. To select the best model, we tested the root mean square error (RMSE) for the samples and obtained the results for different hidden layers as shown in Table 3. The test sample had the lowest RMSE of 0.206204 with 25 neurons in the Hidden layer, the learning rate of 0.0002 , and 150,000 iterations. Therefore, the hidden layer with 25 neurons model is the one that give the best prediction.

$<$ Table 3 about here $>$

\subsection{Multivariate Adaptive Regression Splines (MARS)}

To analyze the data using MARS model, we first used the data for the previous 62 months to establish the MARS regression model and then we used the data for the following 16 months as the test samples. The number of tourists who visited Taiwan in the previous 12 months was independent variable while the current number of tourists was dependent variable. The results of the analysis obtained by using a MARS regression model indicated the adjusted $\mathrm{R}^{2}$ of 0.637 , mean square of 244,492,132 and the significant independent variable X1 with a significant value at $100 \%$. The equation for the MARS regression is shown as follows:

$\mathrm{BA} 1=\max (0, \mathrm{X} 1-212854.016)$;

$\mathrm{Y}=2537648.359+0.665 \times \mathrm{BF} 1$

The result of the prediction from January to December 2009 shows that RMSE is $8,895.09$, MAD is $76,986.57$, and MAPE is $17.72 \%$.

\subsection{Comparison of the three analytical models}

The three best models obtained by ARIMA, BPN, and MARS respectively, were used to forecast the number of tourists from March 2009 to June 2010. The results are shown in Table 4. Figure 3 shows that the forecast of the number of tourists by the seasonal $\operatorname{ARIMA}(2,0,2) \times(2,0,1) 12$ model is relatively closer to the actual number of tourists. Table 5 shows the validity of the 3 forecasting models assessed by the root mean square error (RMSE), mean absolute deviation (MAD), and the average percentage error (MAPE). In comparison of the 3 error values, it is found that ARIMA's value is the smallest, indicating that ARIMA $(2,0,0) \times(2,0,2) 12$ is the best prediction model.

$$
\begin{aligned}
& <\text { Table } 4 \text { about here> } \\
& <\text { Figure } 3 \text { about here> } \\
& <\text { Table } 5 \text { about here }>
\end{aligned}
$$

Table 6 shows the result of ARIMA, BPN and MARS, which predicted the number of tourists' descriptive statistics. Then use nonparametric method's friedman way to check the three tourists' number forecasted by ARIMA, BPN and MARS have significant difference or not. In addition, the result is as table 7, which has significant difference in these three models. Therefore, we can sure that the ARIMA has smallest error in results forecasted by three forecasting models. Thus, ARIMA is the best forecasting model.

$$
\begin{aligned}
& <\text { Table } 6 \text { about here }> \\
& <\text { Table } 7 \text { about here }>
\end{aligned}
$$

\section{Conclusions}

Tourism has become an important global industry. According to the research study of the World Travel \& Tourism Council, the global tourism will experience a growing trend in the future, thus, every country should place more and more emphasis on the tourism; and forecasting tourism demand will become more and more essential. In this study, three types of forecast models, ARIMA, ANN, and MARS, were used for the analysis. The aim was to find out the most accurate model for forecasting tourism demand. The results of this study revealed that the MAPE of the ARIMA forecast model is less than the other two models. ARIMA model showed the best forecasting ability. The MAPE of MARS had the highest values indicating that its forecasting ability is the worst. The MAPE of ANN was between the other two models, indicating that its forecasting ability is normal. 
The ARIMA model indicated the best forecasting ability. This result is different from that of Burger et al. (2001) who showed the ANN model forecasts better compared to the ARIMA model. In this study, the MAPE of the seasonal ARIMA $(2,0,2) \times(2,0,1)_{12}$ model was $5.1 \%$ while Burger et al. (2001) reported the MAPE of ARIMA of $11.3 \%$. Cho (2003) found that the MAPE is between $8.24 \%$ and $44.52 \%$, using the ARIMA analysis of the six regions. In this study, the MAPE of ARIMA model had the lowest value. Burger et al. (2001) found that the time-series model is the non-seasonal ARIMA model. Cho (2003) obtained a seasonal ARIMA model, which analyzes the number of tourists who visit Hong Kong from six different countries and regions. Diverse characteristics of tourists from various regions can explain different results of the above time-series models. The difference between the aggregate number of tourists in a region and the number of tourists from separate areas of origins can also explain the discrepancies between different findings. Moreover, the changing economic conditions with seasonal difference can also affect the accuracy of the forecasts.

From the results of the ANN model, Cho (2003) analyzed the tourists from the United States, Japan, Taiwan, Korea, the United Kingdom, and Singapore to Hong Kong separately. ANN predicted tourism demand for the 12 months with the MAPE of $10.11 \%, 10.32 \%, 8 \%, 9.32 \%, 13.32 \%$, and $11.99 \%$, respectively. Burger et al. (2001) predicted the tourism demand for 12 months with the MAPE of $11 \%$. In this study, BNP predicted tourism demand for 12 months with the MAPE of $10.96 \%$, which is very close to the results of the two previous studies. The ANN model showed similar results regardless of the circumstances, and thus it is a more stable prediction model.

The MARS model showed the worst predictive power. This could be because the main purpose of MARS is to select several BF sections indicating that many different independent variables contribute to the dependent variables. However, this study comprised only one BF set in the analytical results. The tourism demand from the previous 12 months was used as the independent variable. The homogeneity of independent variable was too high, which may have accounted for the selection of only one BF, forming a bad predicted outcome.

To understand the difference between the aggregate number of tourist and the number of tourists from separate origins using time-series ARIMA forecast model and to select the best forecast model, the future research could use time-series ARIMA model to predict the aggregate number of tourists in the same area as well as the number of tourists from separated origins. Future studies could also use relevant economic conditions as variables, e.g., exchange rate, CPI, GDP, or hotel accommodation price, among others to predict and analyze the number of tourists, to understand the effects of various economic conditions variables on the number of tourists; and to compare these effects using ARIMA, ANN, and MARS or other different time-series models.

\section{References}

Berry, M. J. A., \& Linoff, G. (1997). Data Mining Technique for Marketing, Sale, and Customer Support. Wiley Computer.

Box, G. E. P. \& Jenkins, G. M. (1976). Time series analysis: forecasting and control. San Francisco: Holden-Day Inc.

Burger, C.J.S.C., Dohnal, M. Kathrada, M. \& Law, R. (2001). A practitioners guide to time-series methods for tourism demand forecasting - a case study of Durban, South Africa. Tourism Management, 22, 403-409. doi:10.1016/S0261-5177(00)00068-6, http://dx.doi.org/10.1016/S0261-5177(00)00068-6

Chiu, C. C., Shao, Y. J. \& Lee, T. S. (2003). Identification of Process Disturbance Using SPC/EPC and Neural Networks. Journal of Intelligent Manufacturing, 14(3), 379-388. doi:10.1023/A:1024657911399, http://dx.doi.org/10.1023/A:1024657911399

Cho,V. (2003). A comparison of three different approaches to tourist arrival forecasting. Tourism Management, 24, 323-330. doi:10.1016/S0261-5177(02)00068-7, http://dx.doi.org/10.1016/S0261-5177(02)00068-7

Coshall, J. T. (2005). A selection strategy for modelling UK tourism flows by air to European destinations. Tourism Economics, 11, 141-158. doi:10.5367/0000000054183487, http://dx.doi.org/10.5367/0000000054183487

De Gooijer, J. G., Ray, B. K. \& Krager, H., (1998). Forecasting Exchange Rates Using Time Series MARS. Journal of International Money and Finance, 17 (3), 513-534. doi:10.1016/S0261-5606(98)00017-5, http://dx.doi.org/10.1016/S0261-5606(98)00017-5

Fish, K. E., Barnes, J. H. \& Aiken, M. W. (1995). Artificial Neural Networks: A New Methodology for Industrial Market Segmentation. Industrial Marketing Management, 24, 431-438. doi:10.1016/0019-8501(95)00033-7, http://dx.doi.org/10.1016/0019-8501(95)00033-7 
Freeman, J. A. \& Skapura, D. M. (1992). Neural Networks Algorithms, Applications, and Programming Techniques. Addison-Wesley Publishing Company.

Friedman, J. H. (1991). Multivariate Adaptive Regression Splines (with discussion). Annals of Statistics, 19, 1-141. doi:10.1214/aos/1176347963, http://dx.doi.org/10.1214/aos/1176347963

Huang, J-H. \& Min, J. C.H. (2002). Earthquake devastation and recovery in tourism: the Taiwan case. Tourism Management, 23, 145-154. doi:10.1016/S0261-5177(01)00051-6, http://dx.doi.org/10.1016/S0261-5177(01)00051-6

Huarng, K-H., Moutinho, Luiz. \& Yu, T. H-K. (2006). An Advanced Approach to Forecasting Tourism Demand in Taiwan. Journal of Travel \& Tourism Marketing, 21(4), 15-24.

Kim, J. H., \& Moosa, I. A. (2005). Forecasting international tourist flows to Australia: A comparison between the direct and indirect methods. Tourism Management, 26, 69-78. doi:10.1016/j.tourman.2003.08.014, http://dx.doi.org/10.1016/j.tourman.2003.08.014

Kulendran, N., \& Shan, J. (2002). Forecasting China's monthly inbound travel demand. Journal of Travel \& Tourism Marketing, 13, 5-19. doi:10.1300/J073v13n01_02, http://dx.doi.org/10.1300/J073v13n01_02

Law, R. (2000). Back-propagation learning in improving the accuracy of neural network-based tourism demand forecasting. Tourism Management, 21, 331-340. doi:10.1016/S0261-5177(99)00067-9, http://dx.doi.org/10.1016/S0261-5177(99)00067-9

Lee, T. S. \& Chiu, C. C. (2002). Neural Network Forecasting of an Opening Cash Price Index. International Journal of Systems Science, 33 (3), 229-237. doi:10.1080/00207720110092216, http://dx.doi.org/10.1080/00207720110092216

Lee, T. S., Chiu, C. C., Lu, C. J., \& Chen, I. F. (2002). Credit Scoring Using the Hybrid Neural Discriminant Technique. Expert Systems with Applications, 23 (3), 245-254. doi:10.1016/S0957-4174(02)00044-1, http://dx.doi.org/10.1016/S0957-4174(02)00044-1

Leung, M. T., Chen, A. S., \& Daouk, H. (2000). Forecasting Exchange Rates Using General Regression Neural Networks, Computers and Operations Research, 27, 1093-1110. doi:10.1016/S0305-0548(99)00144-6, http://dx.doi.org/10.1016/S0305-0548(99)00144-6

Lim, C. \& McAleer, M. (2002). Time-series forecasts of international travel demand for Australia. Tourism Management, 23, 389-396. doi:10.1016/S0261-5177(01)00098-X, http://dx.doi.org/10.1016/S0261-5177(01)00098-X

Min, J. C. H. (2005). The Effect of the SARS Illness on Tourism in Taiwan: An Empirical Study. International Journal of Management, 22(3), 497-508.

Ministry of Transportation \& Communications, ROC. (2009). Project Vanguard for Excellence in Tourism, 2009. Taiwan, ROC.

Palmer, A., Jose Montano, J. J., \& Sese, A. (2006). Designing an artificial neural network for forecasting tourism time-series. Tourism Management, 27, 781-790. doi:10.1016/j.tourman.2005.05.006, http://dx.doi.org/10.1016/j.tourman.2005.05.006

Pankratz, A. (1983). Forecasting with univariate box-jenkins models. New York: Wiley. doi:10.1002/9780470316566, http://dx.doi.org/10.1002/9780470316566

Song, H., \& Li, G. (2008). Tourism demand modelling and forecasting-A review of recent research. Tourism Management, 29, 203-220. doi:10.1016/j.tourman.2007.07.016, http://dx.doi.org/10.1016/j.tourman.2007.07.016

Steinberg, D., Bernard, B., Phillip, C. \& Kerry, M., (1999). MARS User Guide, Salford Systems, San Diego, CA.

Vellido, A., Lisboa, P. J. G. \& Vaughan, J., (1999). Neural Networks in Business: A Survey of Applications (1992-1998), Expert Systems with Applications, 17, 51-70. doi:10.1016/S0957-4174(99)00016-0, http://dx.doi.org/10.1016/S0957-4174(99)00016-0

World Travel \& Tourism Council (2009).TRAVEL \& TOURISM ECONOMIC IMPACT Executive Summary, 2009. London,UK. http://www.wttc.org/bin/pdf/original_pdf_file/exec_summary_2009.pdf

Zhang, G., Patuwo, B. E. \& Hu, M. Y. (1998). Forecasting with Artificial Neural Networks: TheState of the Art", International Journal of Forecasting, 14, 35-62. doi:10.1016/S0169-2070(97)00044-7, http://dx.doi.org/10.1016/S0169-2070(97)00044-7 
Table 1. ARIMA models

\begin{tabular}{|c|c|c|c|c|}
\hline & models & Adjusted $\mathrm{R}^{2}$ & AIC & $\mathrm{SBC}$ \\
\hline 1 & $\operatorname{ARIMA}(1,0,2) \times(1,0,0)_{12}$ & 0.581721 & 22.35854 & 22.51151 \\
\hline 2 & $\operatorname{ARIMA}(2,0,1) x(1,0,0)_{12}$ & 0.568583 & 22.38947 & 22.54243 \\
\hline 3 & $\operatorname{ARIMA}(2,0,2) \times(1,0,0)_{12}$ & 0.578387 & 22.38450 & 22.57571 \\
\hline 4 & $\operatorname{ARIMA}(1,0,1) x(1,0,2)_{12}$ & 0.815166 & 21.55987 & 21.75108 \\
\hline 5 & $\operatorname{ARIMA}(1,0,2) \times(1,0,2)_{12}$ & 0.811148 & 21.59891 & 21.82835 \\
\hline 6 & $\operatorname{ARIMA}(2,0,1) \times(1,0,2)_{12}$ & 0.812271 & 21.59295 & 21.82239 \\
\hline 7 & $\operatorname{ARIMA}(2,0,2) \times(1,0,2)_{12}$ & 0.801150 & 21.66751 & 21.93519 \\
\hline 8 & $\operatorname{ARIMA}(1,0,0) \times(2,0,0)_{12}$ & 0.566059 & 22.29315 & 22.40898 \\
\hline 9 & $\operatorname{ARIMA}(1,0,1) \times(2,0,0)_{12}$ & 0.647691 & 22.10359 & 22.25802 \\
\hline 10 & $\operatorname{ARIMA}(2,0,0) \times(2,0,0)_{12}$ & 0.575394 & 22.29024 & 22.44468 \\
\hline 11 & $\operatorname{ARIMA}(2,0,1) \times(2,0,0)_{12}$ & 0.640001 & 22.14352 & 22.33657 \\
\hline 12 & $\operatorname{ARIMA}(2,0,2) \times(2,0,0)_{12}$ & 0.636569 & 22.17084 & 22.40249 \\
\hline 13 & $\operatorname{ARIMA}(1,0,0) \times(2,0,1)_{12}$ & 0.801107 & 21.53185 & 21.68628 \\
\hline 14 & $\operatorname{ARIMA}(2,0,0) \times(2,0,1)_{12}$ & 0.798822 & 21.56161 & 21.75465 \\
\hline 15 & $\operatorname{ARIMA}(1,0,0) \times(2,0,2)_{12}$ & 0.804415 & 21.53342 & 21.72646 \\
\hline 16 & $\operatorname{ARIMA}(2,0,0) \times(2,0,2)_{12}$ & 0.801695 & 21.56505 & 21.79671 \\
\hline 17 & $\operatorname{ARIMA}(2,0,1) \times(2,0,2)_{12}$ & 0.770870 & 21.72683 & 21.99709 \\
\hline
\end{tabular}

Table 2. Results predicted by ARIMA models

\begin{tabular}{|c|c|c|c|c|}
\hline & Models & RMSE & MAD & MAPE \\
\hline 1 & $\operatorname{ARIMA}(1,0,2) \times(1,0,0) 12$ & 59392.46 & 51501.55 & 12.32259 \\
\hline 2 & $\operatorname{ARIMA}(2,0,1) \times(1,0,0)_{12}$ & 55191.73 & 45501.21 & 10.66327 \\
\hline 3 & $\operatorname{ARIMA}(2,0,2) \times(1,0,0)_{12}$ & 58307.09 & 50060.11 & 11.97533 \\
\hline 4 & $\operatorname{ARIMA}(1,0,1) \times(1,0,2)_{12}$ & 38712.18 & 30814.17 & 7.574784 \\
\hline 5 & $\operatorname{ARIMA}(1,0,2) \times(1,0,2)_{12}$ & 38659.64 & 31699.37 & 7.677715 \\
\hline 6 & $\operatorname{ARIMA}(2,0,1) \times(1,0,2)_{12}$ & 38474.73 & 30386.50 & 7.472108 \\
\hline 7 & $\operatorname{ARIMA}(2,0,2) \times(1,0,2)_{12}$ & 38155.34 & 30713.86 & 7.487305 \\
\hline 8 & $\operatorname{ARIMA}(1,0,0) \times(2,0,0)_{12}$ & 52879.95 & 44941.82 & 10.68264 \\
\hline 9 & $\operatorname{ARIMA}(1,0,1) \times(2,0,0))_{12}$ & 57637.91 & 46208.06 & 10.82220 \\
\hline 10 & $\operatorname{ARIMA}(2,0,0) \times(2,0,0)_{12}$ & 53396.92 & 44038.70 & 10.53357 \\
\hline 11 & $\operatorname{ARIMA}(2,0,1) \times(2,0,0)_{12}$ & 57667.57 & 46020.39 & 10.77251 \\
\hline 12 & $\operatorname{ARIMA}(2,0,2) \times(2,0,0)_{12}$ & 73099.04 & 62543.72 & 14.48030 \\
\hline 13 & $\operatorname{ARIMA}(1,0,0) \times(2,0,1)_{12}$ & 44144.30 & 37971.05 & 8.959833 \\
\hline 14 & $\operatorname{ARIMA}(2,0,0) \times(2,0,1)_{12}$ & 43115.15 & 36960.37 & 8.735764 \\
\hline 15 & $\operatorname{ARIMA}(1,0,0) \times(2,0,2)_{12}$ & 37746.52 & 30244.02 & 7.374004 \\
\hline 16 & $\operatorname{ARIMA}(2,0,0) \times(2,0,2)_{12}$ & 37466.43 & 29544.56 & 7.220028 \\
\hline 17 & $\operatorname{ARIMA}(2,0,1) \times(2,0,2)_{12}$ & 48795.08 & 39413.41 & 9.133568 \\
\hline
\end{tabular}


Table 3. BPN models

\begin{tabular}{|c|c|c|c|c|}
\hline $\begin{array}{c}\text { hidden layer } \\
\text { neurons }\end{array}$ & $\begin{array}{c}\text { learning } \\
\text { rate }\end{array}$ & iterations & $\begin{array}{c}\text { training samples } \\
\text { RMSE }\end{array}$ & test samples RMSE \\
\hline 22 & 0.0006 & 55000 & 0.042041 & 0.206975 \\
\hline 23 & 0.0004 & 90000 & 0.041363 & 0.206438 \\
\hline 24 & 0.0005 & 70000 & 0.041723 & 0.209868 \\
\hline 25 & 0.0002 & 150000 & 0.041779 & 0.206204 \\
\hline 26 & 0.0006 & 60000 & 0.041041 & 0.208629 \\
\hline
\end{tabular}

Table 4. The number of tourists predicted by ARIMA, BPN and MARS

\begin{tabular}{|c|c|c|c|c|c|}
\hline year & month & Actual & ARIMA Predicted & BPN Predicted & MARS Predicted \\
\hline 2009 & 3 & 395201 & 425948 & 331660 & 339721 \\
\hline 2009 & 4 & 448486 & 420945 & 316920 & 313614 \\
\hline 2009 & 5 & 366375 & 434264 & 323840 & 321518 \\
\hline 2009 & 6 & 321383 & 401713 & 338070 & 338651 \\
\hline 2009 & 7 & 346718 & 334246 & 328740 & 316587 \\
\hline 2009 & 8 & 367491 & 357524 & 331160 & 319447 \\
\hline 2009 & 9 & 340645 & 338914 & 336320 & 316663 \\
\hline 2009 & 10 & 368212 & 364653 & 340800 & 329726 \\
\hline 2009 & 11 & 410489 & 390652 & 349550 & 346358 \\
\hline 2009 & 12 & 449806 & 419970 & 337730 & 296369 \\
\hline 2010 & 1 & 345981 & 353162 & 332700 & 313936 \\
\hline 2010 & 2 & 387143 & 374380 & 365850 & 375072 \\
\hline 2010 & 3 & 516512 & 458328 & 394540 & 410521 \\
\hline 2010 & 4 & 506400 & 468473 & 369500 & 355896 \\
\hline 2010 & 5 & 505856 & 454395 & 449160 & 325964 \\
\hline 2010 & 6 & 470447 & 3690 & 360 \\
\hline
\end{tabular}

Table 5. RMSE, MAD, and MAPE values

\begin{tabular}{|l|c|c|c|}
\hline & RMSE & MAD & MAPE \\
\hline ARIMA & 37466.43 & 29544.56 & $7.22 \%$ \\
\hline BPN & 80202.12 & 65371.25 & $14.71 \%$ \\
\hline MARS & 88895.09 & 76986.75 & $17.72 \%$ \\
\hline
\end{tabular}

Table 6. The number of tourists' descriptive statistics predicted by ARIMA, BPN and MARS

\begin{tabular}{|c|c|c|c|c|c|}
\hline $\begin{array}{c}\text { Predicted of the } \\
\text { number of tourists }\end{array}$ & $\mathrm{N}$ & Mean & Std. Deviation & Minimum & Maximum \\
\hline ARIMA & 16 & 402920.44 & 44768.881 & 334246 & 468473 \\
\hline BPN & 16 & 345911.88 & 21411.128 & 316920 & 394540 \\
\hline MARS & 16 & 334368.31 & 27727.730 & 296369 & 410521 \\
\hline
\end{tabular}


Table 7. Friedman test's result

\begin{tabular}{|c|r|}
\hline $\mathrm{N}$ & 16 \\
\hline Chi-Square & 26.000 \\
\hline $\mathrm{df}$ & 2 \\
\hline Asymp. Sig. & .000 \\
\hline
\end{tabular}

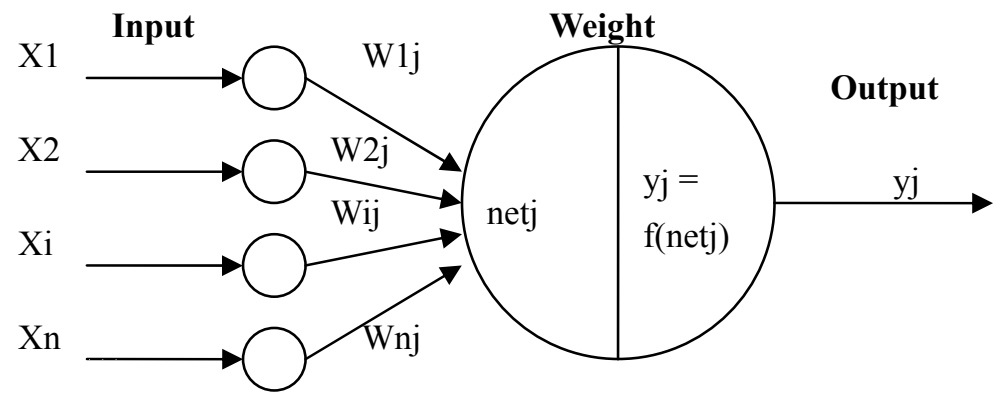

$n e t_{j}=\sum_{i=1}^{N} W_{i j} X_{i}+\theta_{i}$

Figure 1. An artificial neuron

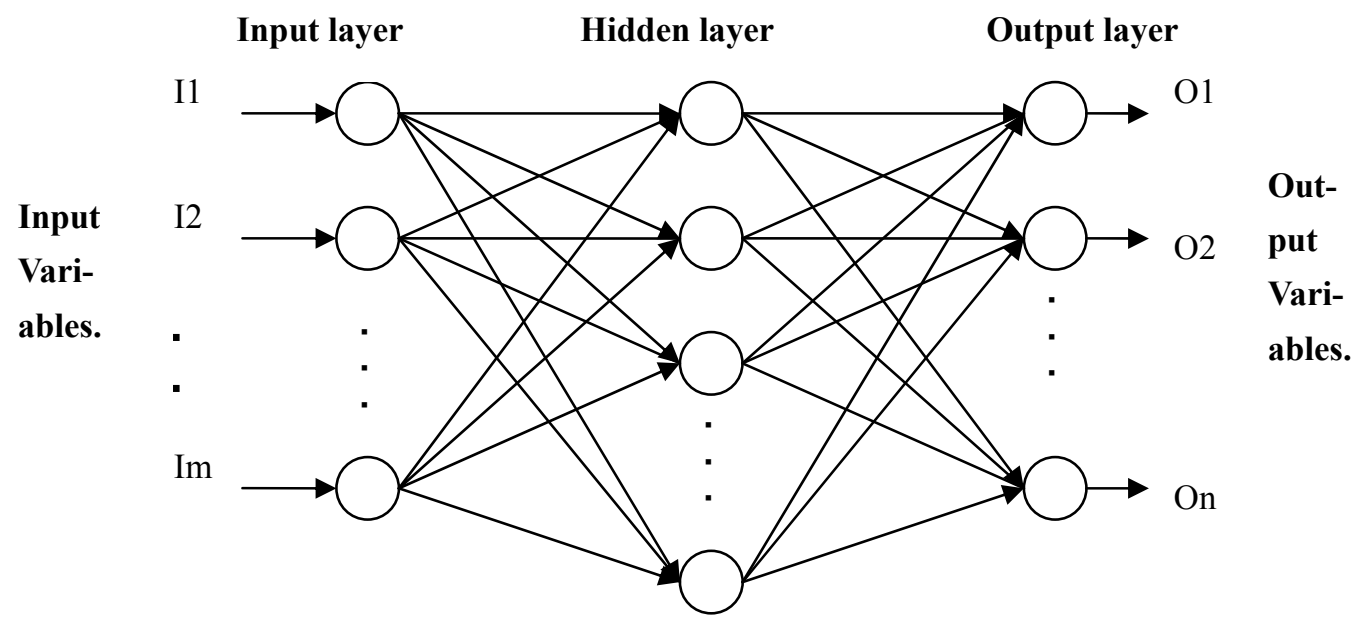

Figure 2. Back-propagation network 


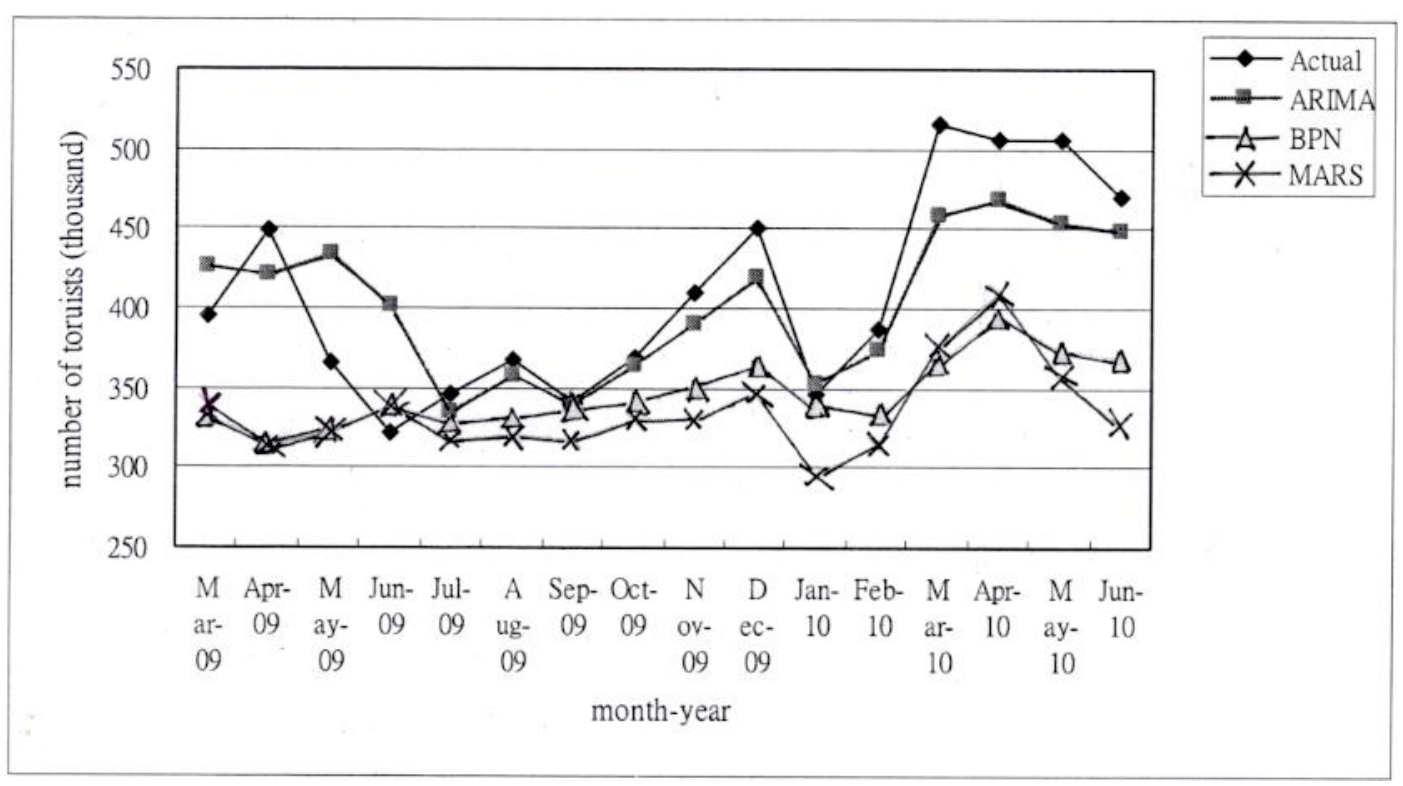

Figure 3. Graphical presentation of actual and predicted values of tourists 